\title{
Injury prevalence across sports: a descriptive analysis on a representative sample of the Danish population
}

\author{
A. M. Bueno ${ }^{1 *}$, M. Pilgaard ${ }^{2}$, A. Hulme ${ }^{3}$, P. Forsberg ${ }^{4}$, D. Ramskov ${ }^{5}$, C. Damsted ${ }^{6}$ and R. O. Nielsen ${ }^{6}$
}

\begin{abstract}
Background: Physical activity plays an important role in public health, owing to a range of health-related benefits that it provides. Sports-related injuries are known to be an important barrier to continued physical activity. Still, the prevalence of injuries on a general population level has not yet been explored in a descriptive epidemiological investigation. The purpose of the questionnaire-based study, therefore, was to describe the prevalence of injury in a representative sample of the Danish population.
\end{abstract}

Methods: Two samples of 10,000 adults (> 15 years) and 6500 children and adolescents ( $7-15$ years) were invited to respond to a web-based questionnaire. Of these, 3498 adults (35.0\%) and 3221 children (49.6\%) responded successfully. The definition of sports injury was time-loss and medical attention-based, inhibiting participants from sports activity for at least 7 days, and/or involved contact with a healthcare professional, respectively.

Results: Amongst adults, 642 (18.4\% [95\%Cl: 17.1\%; 19.6\%]) reported to have had an injury within the past 12 months. Males reported significantly more injuries than females (difference in prevalence proportion: 9.2\%-points [95\%Cl: 6.7\%-points; 11.8\%-points]). The prevalence of injuries was greatest in running $\left(n_{\text {inj }}=198\right)$, football $\left(n_{\text {inj }}=94\right)$ and strength training $\left(n_{\text {inj }}=89\right)$.

Amongst children, 621 (19.3\% [95\%Cl: 17.9\%; 20.6\%]) had been injured. No difference in injury prevalence proportion existed between boys and girls. The prevalence of injuries was greatest in football $\left(n_{i n j}=235\right)$, handball $\left(n_{\text {inj }}=86\right)$ and gymnastics $\left(n_{\text {inj }}=66\right)$.

Conclusions: Sports injuries seem to be very frequent in Denmark, since a total of $18.4 \%$ of the adults and $19.3 \%$ of the children reported having had one or more injuries within the past 12 months, equal to either time lost with physical activity and/or contact to the health care system.

\section{Background}

The health benefits associated with physical activity are well accepted in the scientific literature, particularly since physical activity plays an important role in both the prophylaxis and treatment of a number of lifestyle diseases (Klarlund \& Andersen, 2011). To counteract the deleterious effect of inactivity, which is reportedly the second biggest risk factor for death in Denmark (Eriksen et al., 2016), at least $30 \mathrm{~min}$ of physical activity per day has been recommended for adults by The Danish Health Authority (Klarlund \& Andersen, 2011). Likewise,

\footnotetext{
* Correspondence: Andreas_bueno@hotmail.com

'Department of Clinical Medicine, Aarhus University, Palle Juul-Jensens

Boulevard 82, 8200 Aarhus, Denmark

Full list of author information is available at the end of the article
}

amongst children and adolescents, a minimum level of 90 min per day of physical activity has been recommended. In 2011, the prevalence proportion of physically active children and adults in Denmark was $86 \%$ and $64 \%$, respectively (Laub, 2013). Children aged 7-9 years had the greatest level of physical activity, whereas adults aged above 70 years had the least.

Owing to the health-related benefits from being physically active, it is important to shed light on the barriers for becoming physically active, including those that also prevent individuals from maintaining a physically active lifestyle. Various barriers exist, including a lack of motivation having limited health literacy, time constraints, or being physically impaired (Klarlund and Andersen 2011; Rosenbaum et al. 2016). Another barrier is sports injury, 
which can lead to a temporary or permanent break from the chosen activity of interest. Nielsen et al. (Nielsen et al., 2014) found a median time-to-recovery of almost 3 months amongst injured novice runners, thus leading to reduced health-related benefits due to less activity.

According to the TRIPP model (Finch, 2006), the first step in injury research is to understand the extend of the problem. The prevalence and prevalence proportion of sport injuries has been widely investigated across sports. Unfortunately, such studies have only included groups selected by either one or more criteria, such as specific sport (Jacobsson et al., 2012), level (Hall et al., 2013), age (Scase et al., 2012) or injury type (Maselli et al., 2015). The recruitment of selected groups has further limited the external validity of study results to the general population. In addition, knowledge about the prevalence of sports injuries on a general population level is, alongside injury severity and treatment costs, important in order to identify whether sports injuries are a public health burden, as well as to identify whether certain sports contribute to a larger number of injuries than others (Finch, 2006). To our knowledge, no studies have yet investigated the total prevalence of sport injuries in a general population-based sample, and subsequently compared the prevalence and prevalence proportion of sports injuries between different sports.

Therefore, the primary aim of this study was to add to the literature the prevalence proportion of sport injuries in a representative sample of the general Danish population. The secondary aim was to describe the prevalence and prevalence proportion of injuries in different sports.

\section{Methods}

\section{Design}

The study was designed as a questionnaire-based study. The Danish Data Protection Agency approved the study and in accordance with Danish law, approval from the local ethics committee is only required in studies with an intervention. In primo January 2016, questionnaires were distributed via postal mail by a local company (Rambøll, Denmark, using SurveyXact) to a representative sample of the general Danish population.

\section{Sampling}

The Danish Civil Registration System (CRS), an administrative register established on April 2, 1968, which contains individual-level information on all persons residing in Denmark (and Greenland as of May 1, 1972), was used to identify: (i) a sample of adults consisting of 10.000 persons above 15 years; and, (ii) a sample of children and adolescents consisting of 6.500 persons between 7 and 15 years. A unique ten-digit Civil Personal Register number was assigned to all persons in the CRS which allowed for the identifications of birth date and gender (Schmidt et al., 2014). All 10.000 adults and 6.500 children were randomly selected from CRS.

\section{Data-collection}

The study sample was provided with a written letter by postal mail. For the children and adolescents, the letter was forwarded to the parent who was encouraged to help with the questionnaire. The letter contained a short introductory text about the survey history, method and aim, and contained a person-specific code, which was then used to access a web-based questionnaire. The recipients were encouraged to access the web-based questionnaire through a standard tablet or computer, and informed to complete all questions.

In January 2016, non-responders received a reminder by postal mail. In cases of no response, they were contacted by phone. In March, they received a second postal mail reminder.

A flow-chart is presented in Fig. 1.

\section{Questionnaire}

The questionnaire, "Habits of Activities and Sports of the Danes", consisted of 42 questions focusing on activity habits in every aspect. Similar versions of the survey had previously been distributed to the Danish population on eight previous occasions, starting in the sixties. However, the questionnaire distributed in 2016 was the first to include questions pertaining to sports injury. In the questionnaire, a sport-related injury, dichotomized into "yes" or "no", was defined as "an injury sustained in relation to sport/exercise, which has prevented you from participating in sport/exercise for at least seven days, and/or which required contact with health professionals (doctor, physiotherapist or other)", pooling single and multiple injuries together. The injury definition including "and/or" in regard to time loss and medical attention was chosen to keep the questionnaire as short as possible but still comparable to definitions used in other studies. The injury had to be present within the past 12 months, but could have been sustained before this period, however it was unknown whether prevention from activity or contact to health professionals, or both, was the reason.

The responders had to report gender, age, activity in general, activity-specific participation, injury status, and the specific activity causing the injury (the latter four categories focused on the past 12 months). Only activities with regular participation were mentioned, and multiple activities could be noted as having caused the injury. The length of 12 months was used to avoid the influence of seasonal variation in affecting changes to sports participation levels. The activity options in the questionnaire were based on knowledge from previous questionnaires, and included the most frequently played sports and activities 


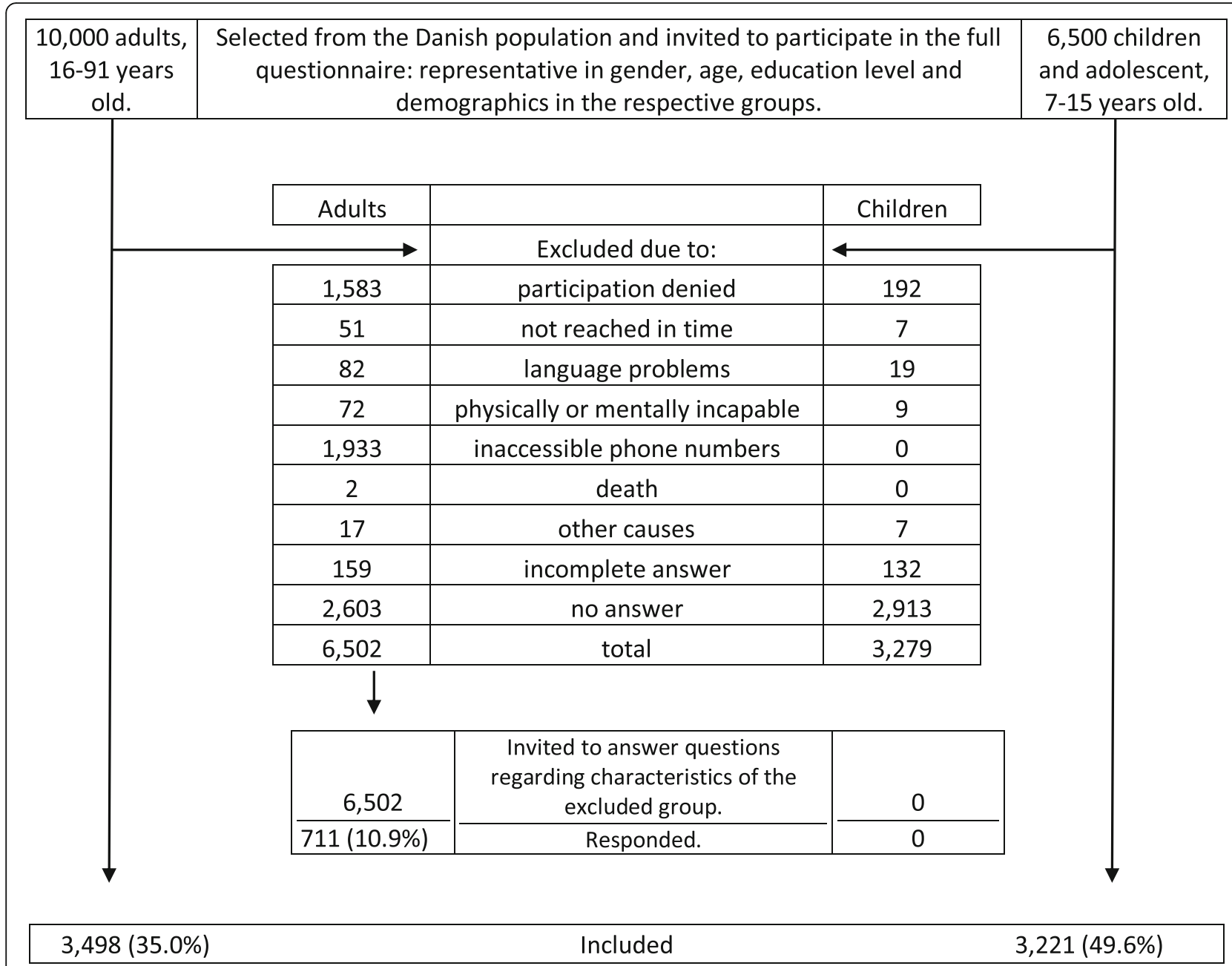

Fig. 1 Recruitment Flowchart

in Denmark (IDAN Rapport 2011). An option to add an activity under the label "others" was included.

\section{Statistics}

In the descriptive analysis, an injury prevalence (IP) was calculated representing the number of individuals reporting an injury, while the injury prevalence proportion (IPP) was the number of individuals reporting injuries divided by total number of respondents.

In the comparative analyses, prevalence proportion ratio was used to describe the association between injury prevalence proportion and age-groups, solely in the adult group. Prevalence proportion difference, by binomial regression, was used to compare the association between injury prevalence proportion and gender, both among adults and children.

An uneven distribution of multiple age and gender existed between responders and non-responders, including gender and age among adults, thus the adult group were analytically weighted so that each unit was inversely proportional to the variance of the observation. The weight reduced the discrepancy in age and gender in the responders compared with non-responders. No weight was used amongst children due to even response proportions between gender and age groups.

In the calculations focusing the "active" part of the sample, the persons who reported sports-related injuries within the past 12 months without reporting regular participation in any sports activity the past 12 months, were excluded, showing in the different number of injuries among all compared to the active part. This accounts for the calculations of injuries among "active", "injuries across sports" and comparative analysis of age-groups, for both children and adults. The wording "active" in the present paper, refers to a participant answering to have been regularly participating in at least one activity within the past 12 months.

The data management and statistical analyses were handled in Stata (Stata/IC 14.0 for Mac, College Station, TX, USA), while Excel (Microsoft Excel for Mac, version 15.19.1) was used to compute Tables. 


\section{Results}

Of the 10,000 adults receiving a questionnaire, 3498 (35.0\%) responded. After weighting the data, the sample consisted of 1719 males and 1779 females, of which $82.4 \%$ reported regularly being physically active, within the past year. A total of 642 (IPP $=18.4 \%$ (95\% CI: $17.1 \% ; 19.6 \%)$ ) reported to have been injured at least once within the past 12 months. Males reported significantly more injuries (9.2\%-points (95\% CI: 6.7\%-points; $11.8 \%$-points)) than females, since the prevalence and prevalence proportion of injuries amongst males were 396 (23.1\% (95\% CI: 21.1\%; 25.0\%)) and amongst females 246 (13.8\% (95\% CI: $12.2 \%$; 15.4\%)).

Of the 2884 active adults, 620 persons reported an injury, equivalent to a prevalence proportion of $21.5 \%$ (95\% CI: 20.0\%; 23.0\%). Among active adults, $27.4 \%$ (95\% CI: $25.1 \% ; 29.7 \%)$ and $15.9 \%(14.0 \% ; 17.8 \%)$ of the males and females, respectively, reported injuries.

Of the 6500 children receiving a questionnaire, 3221 (49.6\%) responded, of which $95.2 \%$ were regularly active within the last year. Injuries were presented in 621 (19.3\% (95\% CI: $17.9 \%$; 20.6\%)) children in the past 12 months. The injury prevalence proportion was similar amongst boys (19.5\% (95\% CI: 17.5\%; 21.4\%)) and girls (19.1\% (95\% CI: 17.1\%; 21.0\%)). Amongst physically active children, $19.9 \%$ (95\% CI: $18.5 \%$; $21.3 \%$ ) reported an injury.

Both adults (Table 1) and children (Table 2) reported in which activities they regularly participated and in case of an injury, which activity had been related to the injury. Amongst adults, running was the sport contributing with the most injuries $\left(\mathrm{n}_{\mathrm{inj}}=198\right)$, followed by football $\left(\mathrm{n}_{\mathrm{inj}}=94\right)$ and strength training $\left(\mathrm{n}_{\mathrm{inj}}=89\right)$. Amongst children, football $\left(\mathrm{n}_{\mathrm{inj}}=235\right)$, handball $\left(\mathrm{n}_{\mathrm{inj}}=\right.$ 86) and gymnastics $\left(n_{i n j}=66\right)$ were the sports with the highest prevalence of injuries.

Table 3 shows the injury prevalence proportion in different age-groups amongst adults and adolescents. These estimates focus only "physically active". The prevalence proportion ratio is calculated with the youngest group, 16-19 years, as reference. The prevalence proportion of injured is continuously decreasing from the youngest to the oldest with only one plateau at $20-29$ and 30-39.

\section{Discussion}

To our knowledge, no peer-reviewed articles have examined the injury prevalence and prevalence proportion of physically active persons in Denmark on a population level. The present study is therefore novel in the sense that contributes to the overall identification of the extent of the injury problem (Finch, 2006). The data presented in this study also suggest that sports injuries are frequent in Denmark, since a total of $18.4 \%$ of the adults and $19.3 \%$ of the children reported having had one or more injuries within the past 12 months, equal to either time lost with physical activity and/or contact to the health care system. We found more injuries amongst males than amongst females. The reason for this difference may be due to gender-specific differences in both physical aspects like anatomy but also psychologically aspects as mentality and behaviour when participating in certain sports. In addition, different preferences may exist between gender in the type of preferred physical activity and the exposure time of these activities, which, may be higher in males, which is detectable in the data set, and could be focused in future studies.

The consequences associated with sports-related injuries in Denmark are still largely unknown. For example, information about injury severity and recovery, potential absenteeism of work, use of therapeutic or surgical interventions, or time before returning to play (which may be equal to absenteeism from the health benefits of physical activity) are needed to understand the full impact from a population-level perspective.

According to Table 1, running was the sport which contributed to the most injuries $\left(\mathrm{n}_{\mathrm{inj}}=198\right)$ among adults, followed by football $\left(\mathrm{n}_{\text {inj }}=94\right)$ and strength training $\left(n_{i n j}=89\right)$. Accordingly, a reduction in the total number of sports injuries in the adult Danish population would benefit from a focus on preventing injuries sustained when running, playing football and engaging in strength training. Similarly, prevention of injuries in children and adolescents may require increased focus on preventing injuries associated with football $\left(\mathrm{n}_{\mathrm{inj}}=235\right)$, handball $\left(\mathrm{n}_{\mathrm{inj}}=86\right)$ and gymnastics $\left(\mathrm{n}_{\mathrm{inj}}=66\right)$ (Table 2). Importantly, no consequences in terms of absenteeism from work, surgery or time-to-recovery were reported. Therefore, some sports with a low injury prevalence, such as riding (7 injuries reported) amongst adults, may lead to severe injuries, such as spinal cord trauma etc., while the impact of injuries in other sports are less severe. This is not shown in the present data. Consequently, this is a major limitation that limited the possibility for evaluating the consequences of injuries across sports.

Table 3 shows the injury prevalence proportion ratio between age groups amongst active. The injury prevalence proportion continuously decrease from the youngest to the oldest, with only one plateau at 20-29 and 30-39. This observed trend could be explained by behavioural changes over time including changes to activity preference, as well as "the healthy athletes bias/ effect" which is based on the rationale that only previously uninjured persons will continue to be active into older age.

The sample of the present study was recruited through CRS. Therefore, the 10.000 adults and 6.500 children 
Table 1 Injuries across sports among adults

\begin{tabular}{|c|c|c|c|c|c|c|c|c|c|}
\hline \multirow{2}{*}{ Adults sport } & \multicolumn{3}{|c|}{ participation } & \multicolumn{3}{|c|}{ IP } & \multicolumn{3}{|c|}{ IPP } \\
\hline & $a$ & $95 \%$ & $\mathrm{Cl}$ & $\overline{n_{\text {inj }}}$ & $95 \%$ & $\overline{\mathrm{Cl}}$ & $\overline{n_{\text {inj }} / a}$ & $95 \%$ & $\mathrm{Cl}$ \\
\hline unning & 1032 & 979 & 1085 & 198 & 173 & 223 & 0,19 & 0,17 & 0,22 \\
\hline football & 248 & 218 & 278 & 94 & 79 & 109 & 0,38 & 0,32 & 0,44 \\
\hline strength & 1047 & 994 & 1100 & 89 & 71 & 107 & 0,09 & 0,07 & 0,10 \\
\hline handball & 87 & 69 & 105 & 34 & 25 & 43 & 0,39 & 0,29 & 0,49 \\
\hline badminton & 193 & 167 & 219 & 24 & 15 & 33 & 0,12 & 0,08 & 0,17 \\
\hline gymnastics & 295 & 263 & 327 & 18 & 10 & 26 & 0,06 & 0,03 & 0,09 \\
\hline hiking & 896 & 845 & 947 & 18 & 10 & 26 & 0,02 & 0,01 & 0,03 \\
\hline oad biking & 275 & 244 & 306 & 15 & 8 & 22 & 0,05 & 0,03 & 0,08 \\
\hline tennis & 79 & 62 & 96 & 14 & 7 & 21 & 0,18 & 0,09 & 0,26 \\
\hline mount. Biking & 211 & 183 & 239 & 13 & 6 & 20 & 0,06 & 0,03 & 0,09 \\
\hline cross fit & 144 & 121 & 167 & 12 & 5 & 19 & 0,08 & 0,04 & 0,13 \\
\hline skiing & 267 & 236 & 298 & 10 & 4 & 16 & 0,04 & 0,01 & 0,06 \\
\hline aerobic & 246 & 216 & 276 & 10 & 4 & 16 & 0,04 & 0,02 & 0,07 \\
\hline martial arts & 56 & 41 & 71 & 9 & 4 & 14 & 0,16 & 0,06 & 0,26 \\
\hline golf & 143 & 120 & 166 & 9 & 3 & 15 & 0,06 & 0,02 & 0,10 \\
\hline bike spinning & 374 & 338 & 410 & 9 & 3 & 15 & 0,02 & 0,01 & 0,04 \\
\hline swimming & 514 & 473 & 555 & 7 & 2 & 12 & 0,01 & 0,00 & 0,02 \\
\hline riding & 61 & 46 & 76 & 7 & 2 & 12 & 0,11 & 0,03 & 0,19 \\
\hline skateboarding & 24 & 14 & 34 & 7 & 3 & 11 & 0,29 & 0,11 & 0,47 \\
\hline basketball & 25 & 15 & 35 & 6 & 2 & 10 & 0,24 & 0,07 & 0,41 \\
\hline volleyball & 47 & 34 & 60 & 5 & 1 & 9 & 0,11 & 0,02 & 0,19 \\
\hline canoe / kayak & 82 & 64 & 100 & 4 & 0 & 8 & 0,05 & 0,00 & 0,10 \\
\hline orientering & 32 & 21 & 43 & 4 & 0 & 8 & 0,13 & 0,01 & 0,24 \\
\hline dance & 154 & 130 & 178 & 4 & 0 & 8 & 0,03 & 0,00 & 0,05 \\
\hline hockey & 27 & 17 & 37 & 3 & - & - & 0,11 & - & - \\
\hline parkour & 13 & 6 & 20 & 2 & - & - & 0,15 & - & - \\
\hline yoga & 303 & 270 & 336 & 2 & - & - & 0,01 & - & - \\
\hline sailing & 35 & 23 & 47 & 2 & - & - & 0,06 & - & - \\
\hline boy scout & 25 & 15 & 35 & 2 & - & - & 0,08 & - & - \\
\hline climbing & 28 & 18 & 38 & 1 & - & - & 0,04 & - & - \\
\hline bowling & 82 & 64 & 100 & 1 & - & - & 0,01 & - & - \\
\hline petanque & 40 & 28 & 52 & 1 & - & - & 0,03 & - & - \\
\hline athletics & 8 & 2 & 14 & 1 & - & - & 0,13 & - & - \\
\hline triathlon & 23 & 14 & 32 & 1 & - & - & 0,04 & - & - \\
\hline roller skating & 58 & 43 & 73 & 1 & - & - & 0,02 & - & - \\
\hline table tennis & 35 & 23 & 47 & 1 & - & - & 0,03 & - & - \\
\hline wind- kite surf & 15 & 7 & 23 & 1 & - & - & 0,07 & - & - \\
\hline hurting & 105 & 85 & 125 & 1 & - & - & 0,01 & - & - \\
\hline handicap sport & 9 & 3 & 15 & 1 & - & - & 0,11 & - & - \\
\hline open water & 13 & 6 & 20 & 0 & - & - & 0,00 & - & - \\
\hline billiard & 52 & 38 & 66 & 0 & - & - & 0,00 & - & - \\
\hline nordic walking & 72 & 56 & 88 & 0 & - & - & 0,00 & - & - \\
\hline pilates & 106 & 86 & 126 & 0 & - & - & 0,00 & - & - \\
\hline
\end{tabular}

Table 1 Injuries across sports among adults (Continued)

\begin{tabular}{|c|c|c|c|c|c|c|c|c|c|}
\hline \multirow{2}{*}{ Adults sport } & \multicolumn{3}{|c|}{ participation } & \multicolumn{3}{|c|}{ IP } & \multicolumn{3}{|c|}{ IPP } \\
\hline & $a$ & $95 \%$ & $\mathrm{Cl}$ & $\overline{n_{\text {inj }}}$ & $95 \%$ & $\overline{\mathrm{Cl}}$ & $\overline{n_{\text {inj }} / a}$ & $95 \%$ & $\mathrm{Cl}$ \\
\hline diving & 33 & 22 & 44 & 0 & - & - & 0,00 & - & - \\
\hline rowing & 26 & 16 & 36 & 0 & - & - & 0,00 & - & - \\
\hline wave surf & 4 & 0 & 8 & 0 & - & - & 0,00 & - & - \\
\hline shooting & 51 & 37 & 65 & 0 & - & - & 0,00 & - & - \\
\hline fishing & 143 & 120 & 166 & 0 & - & - & 0,00 & - & - \\
\hline role playing & 10 & 4 & 16 & 0 & - & - & 0,00 & - & - \\
\hline $\begin{array}{l}\text { Participation, "} \\
I P \text {, injury preva } \\
I P P \text {, injury prev } \\
\text { the proportion } \\
\mathrm{Cl} \text {, confidence } \\
\text { Data are sortec } \\
\text { to lowest }\end{array}$ & $\begin{array}{l}\text { uumbe } \\
\text { ce, " }{ }_{\text {nit }} \\
\text { nce pr } \\
\text { erval } \\
\text { jinjur }\end{array}$ & 1 & , & & & & llts, & & \\
\hline
\end{tabular}

and adolescents were representative of the population of Denmark in a number of variables, such as gender, age, education, ethnicity and demography. The response proportion among adults of $35 \%$ was lower than similar data collection in 2007 (43\%) and 2011 (47\%). Although the response proportion of $35 \%$ was low, the generalizability to the Danish population is presumably better than other studies examining the epidemiology of injury in specific target-populations such as elite athletes or members of certain sports clubs. However, the results in the present study may be affected by selection- and information bias. Owing to the response proportion of $35.0 \%$ amongst adults and 50\% amongst children, it is reasonable to question whether the responders differed from the non-responders, (i.e. non-responders are hypothesized to be less active compared with responders). This selection problem was unsuccessfully handled by inviting the non-responders to answer a few questions describing their characteristics, but only 711 (10.9\%) responded the phone call and the questions answered described the sub-sample insufficiently.

Amongst children, selection bias was less of a problem because of the higher proportion of persons responding, though the level of activity amongst responders may still be higher than non-responders. In summary, the selection problems addressed above may lead to selection bias amongst both adults and children leading to an overestimation of the proportion being injured in this sample altogether. The proportion of injured amongst active in general or across each sport may, however, be unaffected as it is unreasonable to believe that injury either motivates or prevents answering the questionnaire.

\section{Injury definition}

The definition of injury used in the present study is almost similar to the consensus definition for runners, proposed by Yamato et al. (Yamato et al., 2015). It is well known that different injury definitions will find different 
Table 2 Injuries across sports among children

\begin{tabular}{|c|c|c|c|c|c|c|c|c|c|}
\hline \multirow{2}{*}{ Children sport } & \multicolumn{3}{|c|}{ participation } & \multicolumn{3}{|c|}{$\mathbb{I P}$} & \multicolumn{3}{|c|}{ IPP } \\
\hline & $a$ & $95 \%$ & $\mathrm{Cl}$ & $\mathrm{n}_{\mathrm{inj}}$ & $95 \%$ & $\mathrm{Cl}$ & $n_{\text {inj }} / a$ & $95 \%$ & $\mathrm{Cl}$ \\
\hline football & 1177 & 1123 & 1231 & 235 & 208 & 262 & 0,20 & 0,18 & 0,22 \\
\hline handball & 415 & 378 & 452 & 86 & 70 & 102 & 0,21 & 0,17 & 0,25 \\
\hline gymnastics & 762 & 715 & 809 & 66 & 51 & 81 & 0,09 & 0,07 & 0,11 \\
\hline running & 574 & 531 & 617 & 37 & 25 & 49 & 0,06 & 0,04 & 0,08 \\
\hline badminton & 288 & 256 & 320 & 21 & 12 & 30 & 0,07 & 0,04 & 0,10 \\
\hline ridning & 257 & 227 & 287 & 21 & 12 & 30 & 0,08 & 0,05 & 0,12 \\
\hline swimming & 1132 & 1079 & 1185 & 17 & 9 & 25 & 0,02 & 0,01 & 0,02 \\
\hline dancing & 381 & 345 & 417 & 16 & 8 & 24 & 0,04 & 0,02 & 0,06 \\
\hline strength training & 377 & 341 & 413 & 15 & 8 & 22 & 0,04 & 0,02 & 0,06 \\
\hline trampoline & 544 & 502 & 586 & 14 & 7 & 21 & 0,03 & 0,01 & 0,04 \\
\hline martial arts & 208 & 181 & 235 & 14 & 7 & 21 & 0,07 & 0,03 & 0,10 \\
\hline basketball & 81 & 64 & 98 & 10 & 4 & 16 & 0,12 & 0,05 & 0,20 \\
\hline kick scooter & 478 & 438 & 518 & 9 & 3 & 15 & 0,02 & 0,01 & 0,03 \\
\hline parkour & 100 & 81 & 119 & 8 & 3 & 13 & 0,08 & 0,03 & 0,13 \\
\hline skateboarding & 196 & 169 & 223 & 7 & 2 & 12 & 0,04 & 0,01 & 0,06 \\
\hline boy scouting & 345 & 311 & 379 & 7 & 2 & 12 & 0,02 & 0,01 & 0,04 \\
\hline tennis & 117 & 96 & 138 & 6 & 1 & 11 & 0,05 & 0,01 & 0,09 \\
\hline athletics & 65 & 49 & 81 & 5 & 1 & 9 & 0,08 & 0,01 & 0,14 \\
\hline hiking & 190 & 164 & 216 & 4 & 0 & 8 & 0,02 & 0,00 & 0,04 \\
\hline$b m x$ & 45 & 32 & 58 & 4 & 0 & 8 & 0,09 & 0,01 & 0,17 \\
\hline volleyball & 56 & 41 & 71 & 3 & - & - & 0,05 & - & - \\
\hline mountain biking & 111 & 91 & 131 & 3 & - & - & 0,03 & - & - \\
\hline roller skating & 268 & 237 & 299 & 3 & - & - & 0,01 & - & - \\
\hline aerobic teams & 37 & 25 & 49 & 3 & - & - & 0,08 & - & - \\
\hline shooting & 77 & 60 & 94 & 2 & - & - & 0,03 & - & - \\
\hline hockey & 42 & 29 & 55 & 1 & - & - & 0,02 & - & - \\
\hline bike spinning & 66 & 50 & 82 & 1 & - & - & 0,02 & - & - \\
\hline golf & 43 & 30 & 56 & 1 & - & - & 0,02 & - & - \\
\hline table tennis & 75 & 58 & 92 & 1 & - & - & 0,01 & - & - \\
\hline canoe / kayak / rowing & 22 & 13 & 31 & 1 & - & - & 0,05 & - & - \\
\hline sailing & 28 & 18 & 38 & 1 & - & - & 0,04 & - & - \\
\hline surfing & 7 & 2 & 12 & 1 & - & - & 0,14 & - & - \\
\hline ice skating & 75 & 58 & 92 & 1 & - & - & 0,01 & - & - \\
\hline road biking & 34 & 23 & 45 & 0 & - & - & 0,00 & - & - \\
\hline role playing game & 58 & 43 & 73 & 0 & - & - & 0,00 & - & - \\
\hline yoga & 48 & 35 & 61 & 0 & - & - & 0,00 & - & - \\
\hline fishing & 81 & 64 & 98 & 0 & - & - & 0,00 & - & - \\
\hline
\end{tabular}

Participation, "a" number of participants

IP injury prevalence, " $\mathrm{n}_{\text {inj }}$ " number of injuries

IPP injury prevalence proportion in different activities of adults, $\mathrm{n}_{\mathrm{inj}} / \mathrm{a}$ the proportion

$\mathrm{Cl}$ confidence interval

Data are sorted by injury prevalence in descending order from highest to lowest 
Table 3 Comparative analysis of prevalence proportions in different age groups (adults only), with the 16-19 years as the reference group

\begin{tabular}{|c|c|c|c|c|c|c|c|c|c|c|c|c|}
\hline \multirow{2}{*}{ Adults age } & \multicolumn{3}{|c|}{ participants } & \multicolumn{3}{|c|}{ IP } & \multicolumn{3}{|c|}{ IPP } & \multicolumn{3}{|c|}{ IPP-ratio } \\
\hline & a & $95 \%$ & $\mathrm{Cl}$ & $n_{\text {inj }}$ & $95 \%$ & $\mathrm{Cl}$ & $\mathrm{n}_{\mathrm{inj}} / \mathrm{a}$ & $95 \%$ & $\mathrm{Cl}$ & IPP/IPP & $95 \%$ & $\mathrm{Cl}$ \\
\hline $16-19$ & 197 & 170 & 224 & 76 & 63 & 89 & 0,39 & 0,32 & 0,45 & 1 & & \\
\hline $20-29$ & 467 & 428 & 506 & 138 & 119 & 157 & 0,30 & 0,25 & 0,34 & 0,76 & 0,60 & 0,95 \\
\hline 30-39 & 410 & 373 & 447 & 114 & 96 & 132 & 0,28 & 0,23 & 0,32 & 0,71 & 0,58 & 0,88 \\
\hline 40-49 & 494 & 454 & 534 & 124 & 105 & 143 & 0,25 & 0,21 & 0,29 & 0,64 & 0,52 & 0,80 \\
\hline 50-59 & 465 & 426 & 504 & 97 & 80 & 114 & 0,21 & 0,17 & 0,25 & 0,53 & 0,42 & 0,68 \\
\hline $60-69$ & 425 & 388 & 462 & 49 & 36 & 62 & 0,12 & 0,08 & 0,15 & 0,30 & 0,22 & 0,41 \\
\hline $70+$ & 426 & 389 & 463 & 23 & 14 & 32 & 0,05 & 0,03 & 0,08 & 0,14 & 0,09 & 0,22 \\
\hline
\end{tabular}

Participation, "a" number of participants

IP injury prevalence, " $\mathrm{n}_{\text {inj }}$ " number of injuries

IPP injury prevalence proportion in different activities of adults, $\mathrm{n}_{\mathrm{inj}} / \mathrm{a}$ the proportion

IPP-ratio prevalence proportion-ratio, IPP/IPP the ratio between injury proportions

$\mathrm{Cl}$ confidence interval

injury prevalence in the same population. Similar definitions must be used before comparing results produced in epidemiological studies. In the present study, timeloss was used as the first component, since it is commonly used to define injury in many team sports given that it is easier to identify cases of injury (Clarsen \& Bahr, 2014) In individual sports, however, it can be difficult to distinguish between reduced, modified, and/or not participating or participating with pain, thus "timeloss" will appear differently between sports and individuals, and 7 days of inhibition may not appear before severe physical complaint is present. Therefore, injury definition, as second component, also comprised a component: "and/or professional health care attention" which classifies a person as injured, irrespective of whether there has been activity time-loss. The use of "time-loss" has the disadvantage that it is very individual-dependent whether to stop training or just modify it. "Medical attention", on the other hand, is very level-dependent, as people at high level of sports may see physiotherapists regularly to avoid losing valuable training time or important competitions, where less trained persons or beginners may take some time off instead of seeing health care. Thus the use of "and / or" will cover some of this discrepancy and may thereby give a more valid picture of the injury proportions.

\section{Perspective}

Translating Research into Injury Prevention Practice (TRIPP) (Finch, 2006) is a framework to enhance prevention of sports-related injuries in a population. Injury surveillance studies must be conducted to identify if sports injuries are a public-health burden. The prevalence of injuries was demonstrated in the present study. Still, the consequences of these injuries require further investigation to fully understand the burden on public health.
The TRIPP framework highlights the importance of determining aetiology and mechanisms of injury. Bittencourt et al. (Bittencourt et al., 2016) promoted that the value of identifying single or multiple risk factors is limited in a prevention-perspective. In contrast, recognition of complex injury pattern as explanation of injury may be a new beneficial analytical approach (Bittencourt et al., 2016). If the injury pattern is recognized, next step is to develop preventive measures and test of the efficacy of the measures, first in ideal conditions, then implemented a in real world as guidelines for athletes and coaches (Soligard et al., 2016). Finally, additional epidemiological studies will be needed frequently to observe a potential effect of preventive interventions and a decline in injury prevalence on population level. Therefore, similar data collection on the prevalence and prevalence proportion of sports injuries in a sample representative of the Danish population will be conducted in the future. The next investigation made by the Danish Institute for Sports Studies will be in 2019/2020.

\section{Conclusion}

According to the present study, sports injuries seem to be very frequent in Denmark, since a total of $18.4 \%$ of the adults and $19.3 \%$ of the children reported having had one or more injuries within the past 12 months, equal to either time lost with physical activity and/or contact to the health care system.

\section{Authors' contribution}

$C D, D R$ and RON designed the study. MP and PF collected the data. AB, MP, $\mathrm{PF}$ and RON completed the data management and statistical analyses. $A B$, $\mathrm{RON}, \mathrm{CD}, \mathrm{DR}$ and $\mathrm{AH}$ interpreted the data. $\mathrm{AB}$ drafted the manuscript and all remaining authors revised it for important intellectual content. All authors approved the final version to be published.

Ethics approval and consent to participate

The study design and its procedures have been presented to the local ethics committee who, according to the Danish law, did not consider the study for ethical approval, owing to the observational nature of the study. 


\section{Competing interests}

The authors declares that they have no competing interests.

\section{Author details}

'Department of Clinical Medicine, Aarhus University, Palle Juul-Jensens Boulevard 82, 8200 Aarhus, Denmark. ${ }^{2}$ The Danish Institute of Sports Studies, Frederiksgade 78B, 8000 Aarhus, Denmark. ${ }^{3}$ Centre of Human Factors and Sociotechnical Systems. University of the Sunshine Coast, Queensland, Australia. ${ }^{4}$ The Danish Institute of Sports Studies, Kanonbådsvej 4A, 1437 København K, Denmark. ${ }^{5}$ Department of Physiotherapy, University College Northern Denmark, 9000 Aalborg, Denmark. ${ }^{6}$ Section for Sport Science, Department of Public Health, Aarhus University, Dalgas Avenue 4, 8000 Aarhus, Denmark.

Received: 10 December 2017 Accepted: 17 February 2018

Published online: 02 April 2018

\section{References}

Bittencourt NFN, Meeuwisse WH, Mendonca LD, Nettel-Aguirre A, Ocarino JM, Fonseca ST. Complex systems approach for sports injuries: moving from risk factor identification to injury pattern recognition-narrative review and new concept. Br J Sports Med; 2016. https://doi.org/10.1136/bjsports-2015-095850. [Epub ahead of print]

Clarsen B, Bahr R. Matching the choice of injury/illness definition to study setting, purpose and design: one size does not fit all. Br J Sports Med. 2014;48(7):510-2.

Eriksen L, Davidsen M, Jensen H, Ryd J, Strøbæk L, White E, et al. Sygdomsbyrden i Danmark Risikofaktorer [Internet]. 2016. Available from: https:/sundhedsstyrelsen. dk/da/nyheder/2016/ /media/C3ACA2467BEE41B49726532872563FFA.ashx. Accessed 10 July 2016

Finch C. A new framework for research leading to sports injury prevention. J Sci Med Sport. 2006;9(1-2):3-9. discussion 10

Hall C, Friel K, Dong M, Engel L, O'Boyle L, Pasquarella A, et al. Epidemiology of injuries in the elite level female high school lacrosse player. Res Sports Med. 2013;21(3):229-39.

Jacobsson J, Timpka T, Kowalski J, Nilsson S, Ekberg J, Renstrom P. Prevalence of musculoskeletal injuries in Swedish elite track and field athletes. Am J Sports Med. 2012:40(1):163-9.

Klarlund B, Andersen LB. FYSISK AKTIVITET [Internet]. Copenhagen; 2011. Available from: https:/sundhedsstyrelsen.dk/ /media/6B3A4AE698BC42139572C76C5854BA76. ashx. Accessed July 2016.

Laub TB. Danskernes motions- og sportsvaner [Internet]. Copenhagen; 2013. Available from:http://www.idan.dk/vidensbank/downloads/danskernesmotions-og-sportsvaner-2011/5f85b653-3bc0-4749-a385-a1 b10098a64a

Maselli F, Ciuro A, Mastrosimone R, Cannone M, Nicoli P, Signori A, et al. Low back pain among Italian rowers: a cross-sectional survey. J Back Musculoskelet Rehabil. 2015;28(2):365-76.

Nielsen RO, Ronnow L, Rasmussen S, Lind M. A prospective study on time to recovery in 254 injured novice runners. PLoS One. 2014;9(6):e99877.

Rosenbaum AJ, Uhl RL, Rankin EA, Mulligan MT. Social and Cultural Barriers: Understanding Musculoskeletal Health Literacy: AOA Critical Issues. J Bone Joint Surg Am. 2016;98(7):607-15.

Scase E, Magarey ME, Chalmers S, Heynen M, Petkov J, Bailey S. The epidemiology of injury for an elite junior Australian football cohort. J Sci Med Sport. 2012;15(3):207-12.

Schmidt M, Pedersen L, Sorensen HT. The Danish civil registration system as a tool in epidemiology. Eur J Epidemiol. 2014;29(8):541-9.

Soligard T, Schwellnus M, Alonso J-M, Bahr R, Clarsen B, Dijkstra HP, et al. How much is too much? (part 1) International Olympic Committee consensus statement on load in sport and risk of injury. Br J Sports Med. 2016;50(17):1030-41.

Yamato TP, Saragiotto BT, Lopes ADA. Consensus definition of running-related injury in recreational runners: a modified Delphi approach. J Orthop Sports Phys Ther. 2015;45(5):375-80.

\section{Submit your manuscript to a SpringerOpen ${ }^{\circ}$ journal and benefit from:}

- Convenient online submission

- Rigorous peer review

- Open access: articles freely available online

- High visibility within the field

- Retaining the copyright to your article

Submit your next manuscript at $\boldsymbol{\nabla}$ springeropen.com 